\title{
COMPARISON OF GETTERING EFFECTS DURING PHOSPHORUS DIFFUSION FOR ONE- AND DOUBLE-SIDED EMITTERS
}

\author{
A. Schneider ${ }^{1}$, R. Kopecek ${ }^{1}$, G. Hahn ${ }^{1}$, S. Noël ${ }^{2}$, P. Fath ${ }^{1}$ \\ ${ }^{1}$ University of Konstanz, Department of Physics, P.O.Box X916, D-78457 Konstanz, Germany \\ ${ }^{2}$ CEA-Grenoble, DSEN/SPVS/L2C, 38054 Grenoble Cedex 9, France
}

\begin{abstract}
A key issue for future solar cell processes is a diffusion sequence which enables fast and clean production, for example by spin-on and spray-on dopants. These diffusion processes have in common that the emitter diffusion is applied on one wafer side, whereas the $\mathrm{POCl}_{3}$ emitter process leads to double-sided doping. For higher throughput the $\mathrm{POCl}_{3}$ process could be adapted by using one slot for two wafers. This so called back-to-back pro-cess leads to one-sided emitters and increases industrial throughput but could result in lower cell efficiency due to reduced gettering during phosphorus diffusion.

In this study we investigate the difference in solar cell performance for cells processed in a back-to-back and standard $\mathrm{POCl}_{3}$ process. Furthermore, X-ray fluorescence and SIMS measurements were performed on $\mathrm{Cz}$ material to study the effect of emitter over-compensation by aluminium. These experiments should clarify if the phosphorus of double-sided emitter cells is partly overcompensated or diffuses into the Al layer of the rear contact.
\end{abstract}

\section{INTRODUCTION}

The share of multi-crystalline silicon material used in solar cell fabrication permanently increases due to the low cost and good performance of the material. One of the major disadvantages of this material as compared to mono-crystalline wafers is the relatively high defect level (dislocation density, metallic impurities and grain boundaries). These disadvantages for solar cell processing are a result of the ingot growth method and have to be overcome by process sequences increasing material quality.

The main process step to decrease the metallic impurity level is the phosphorus diffusion which can increase minority carrier lifetimes drastically due to gettering. In this gettering process the recombination active metallic impurities are removed out of the active areas of the device and captured in the heavily P-doped gettering layer. This gettering effect accents the importance of diffusion processes and demands best possible knowledge about the diffusion step.
One of the major tasks of solar cell industry is to increase cell throughput by adapted or new process sequences. Regarding the emitter process the throughput could almost be doubled in a standard $\mathrm{POCl}_{3}$ diffusion by using one slot for two wafers, resulting in a so called back-to-back diffusion. This process leads to only onesided emitter cells as for other diffusion processes like spray-on or spin-on doping, influencing the gettering effect [1].

In this study we investigate the difference in gettering of one- and double-sided $\mathrm{POCl}_{3}$ emitter cells. Besides multi-crystalline material the same process sequences were applied to mono-crystalline material to distinguish between gettering effects and cell performance losses due to emitter residues on the back cell side. Experiments with different aluminium rear side thicknesses resulting in varying BSF thicknesses should help to understand if the gettering process is influenced by the amount of aluminium available.

Furthermore, X-ray fluorescence and SIMS measurements were performed on double-sided emitter cells to clarify the effect of compensation of phosphorus by aluminium in the BSF. This study should help to understand if this is due to over-compensation, leaving the phosphorus in electrically inactive states or diffusing it into the aluminium back side contact.

\section{EXPERIMENTAL DETAILS}

The applied process sequence for the solar cells is shown in Figure 1. We used a standard industrial solar cell process sequence with a $\mathrm{POCl}_{3}$ diffusion resulting in a $45 \Omega /$ emitter. For metallization silver front side and aluminium rear side screen-printing were applied.

To enable one-sided emitter diffusion in a $\mathrm{POCl}_{3}$ diffusion furnace two wafers were stored in one slot of the quartz tube.

This study can be divided into three parts:

1. determination of the difference in cell performance of one- and double-sided emitter cells. Lifetime and spectral response measurements were carried out to investigate the results in more detail.

2. variation of aluminium rear side thickness to investigate if gettering changes with aluminium amount on one- and double-sided emitter cells.

3. X-ray fluorescence and SIMS measurements in order to study the effect of phosphorus compensation after aluminium and BSF contact formation 


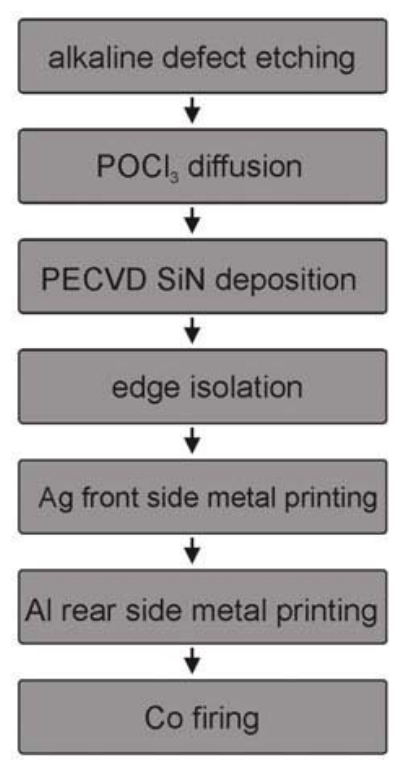

Figure 1: Applied process sequence for mono- and multicrystalline silicon material.

\section{EXPERIMENTAL RESULTS}

\section{Gettering}

In Table 1 the results of multi- and mono-crystalline silicon solar cells with one- and double-sided emitters are presented. The results show a decrease in efficiency of $0.3 \%$ absolute for multi-crystalline and $0.4 \%$ absolute for mono-crystalline silicon material and are averaged over 6 cells, processed on neighboring material (cell size: $10 \times 10 \mathrm{~cm}^{2}$, cell thickness: $330 \mu \mathrm{m}$ ). This decrease is an effect of both, lower $V_{o c}$ and $J_{\text {sc }}$. Whereas for the multicrystalline silicon material this effect could be understood due to differences in gettering for one- and double-sided $\mathrm{POCl}_{3}$ emitters, it is not that clear for mono-crystalline silicon material.

Table 1: Cell results on mono- and multi-crystalline silicon material for one- and double-sided emitters.

\begin{tabular}{|l|c|c|c|c|}
\hline $\begin{array}{c}\text { Diffusion / } \\
\text { Material }\end{array}$ & $\begin{array}{c}\mathrm{V}_{\mathrm{oc}} \\
{[\mathrm{mV}]}\end{array}$ & $\begin{array}{c}\mathrm{J}_{\mathrm{sc}} \\
{\left[\mathrm{mA} / \mathrm{cm}^{2}\right]}\end{array}$ & $\begin{array}{c}\mathrm{FF} \\
{[\%]}\end{array}$ & $\begin{array}{c}\eta \\
{[\%]}\end{array}$ \\
\hline double-sided/mc & 608 & 30.4 & 77.6 & 14.3 \\
\hline one-sided/mc & 604 & 29.7 & 77.9 & 14.0 \\
\hline double-sided/Cz & 616 & 31.2 & 78.1 & 15.0 \\
\hline one-sided/Cz & 612 & 30.8 & 77.6 & 14.6 \\
\hline
\end{tabular}

Gettering should not play a significant role for monocrystalline material, therefore we think of other reasons responsible for this difference. This was proven by spectral response measurements which revealed almost similar effective diffusion lengths and quantum efficiencies for short and long wavelengths for mono-crystalline but not for multi-crystalline cells. Furthermore, gettering could be important for mono-crystalline solar cells if the industrial cell cleaning contaminates the wafers itself.
Performance losses on the rear side by emitter residues, as described by Kaes et al [2], should lead to current losses for double-sided emitter cells. But this effect is in contrast to the current loss observed in this presentation. Therefore another explanation has to be found.

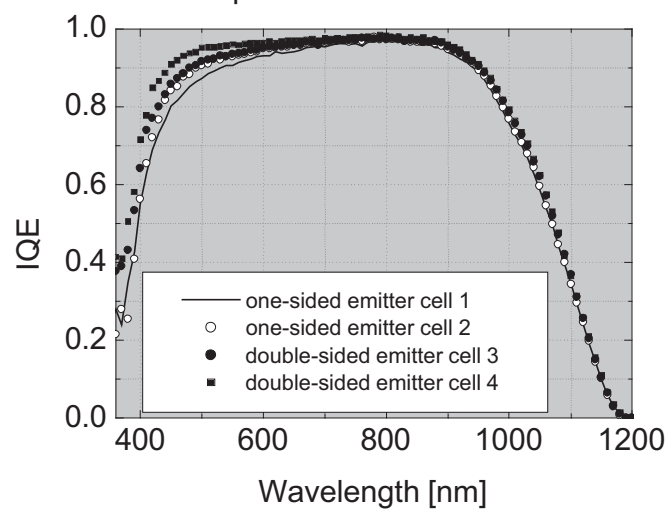

Figure 2: IQE of two one- and two double-sided emitter multi-crystalline $\mathrm{Si}$ solar cells.

The lower cell performance for multi-crystalline $\mathrm{Si}$ material could be directly connected to lower gettering efficiency on the one-sided emitter material. Figure 2 shows the internal quantum efficiency of four cells, two for each emitter sided type. The measurements reveal a lower IQE for shorter and longer wavelengths of onesided emitter cells. The calculated effective diffusion length reveals a drop of $100-200 \mu \mathrm{m}$ as compared to double-sided emitter cells. To investigate this effect further minority carrier lifetimes for two of the multicrystalline cells were measured by $\mu$-PCD (microwave detected photo-conductance decay). Metallization was etched off as well as the BSF and the emitter region. To passivate the surfaces iodine/ethanol solution was used during lifetime measurement. Furthermore the cell was mapped by LBIC to study the gettering effect at long wavelength $(980 \mathrm{~nm})$ on EQE for different grains. Figure 3 shows the results of the LBIC and lifetime measurements.

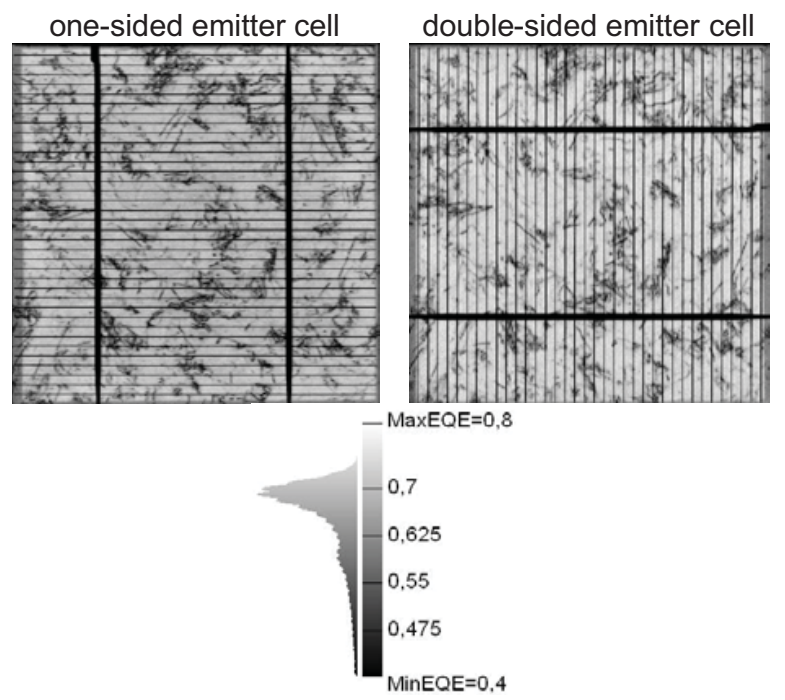



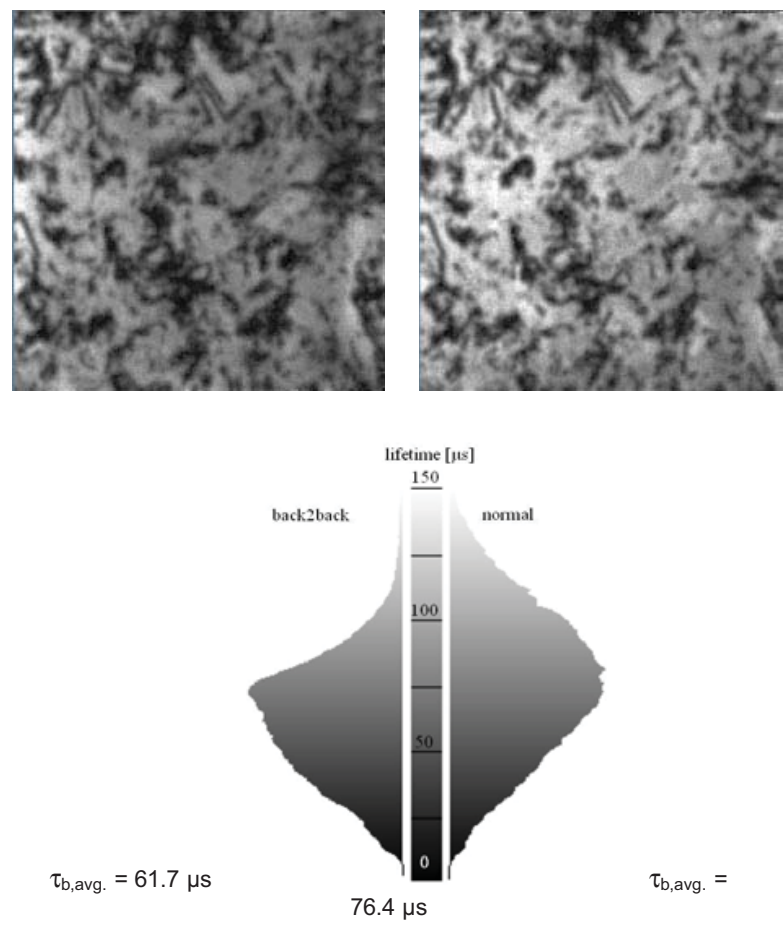

Figure 3: LBIC (top) and lifetime (bottom) mappings of one-sided (left) and double-sided emitter cell (right).

LBIC show a larger EQE at $980 \mathrm{~nm}$ for double-sided emitter cells as compared to one-sided emitter cells. This measurement was confirmed by lifetime mapping, resulting in lower lifetimes for the latter one. Regarding the different grains we could state that mainly grains of higher lifetimes benefit from double-sided gettering effects. As described by different authors lifetime increase after emitter diffusion takes place mainly in high-lifetime areas which are sites of low dislocation densities [3,4].

\section{Effect of Al-gettering}

To study the effect of different paste applications on gettering for back-to-back and standard diffused cells the amount of Al paste was varied during screen-printing.

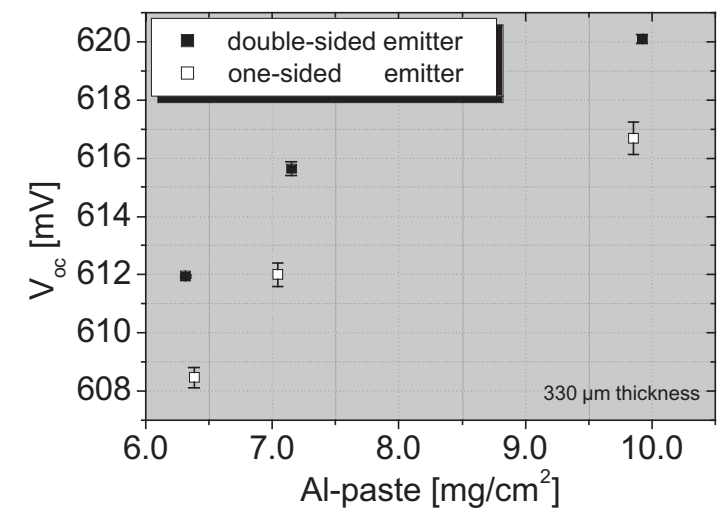

Figure 4: $V_{o c}$ in dependence on amount of aluminium paste deposited for one- and double-sided emitter cells.
The material was $12.5 \times 12.5 \mathrm{~cm}^{2}$ multi-crystalline $\mathrm{Si}$ Solsix of $330 \mu \mathrm{m}$ thickness. The results for $\mathrm{V}_{\text {oc }}$ averaged over 5 cells are displayed in Figure 4 and show lower values for one-sided emitter cells as observed in the experiments before. With lower amount of paste the cell performance is reduced due to the reduced BSF thickness but no effect on gettering with varying paste for one- and double-sided cells could be stated. This experiment was performed two more times on different multi-crystalline materials of different thicknesses to confirm this result. After these experiments we can state that the difference in $V_{o c}$ is due to different P-gettering effects and not due to Al-gettering.

To clarify if the process of BSF formation is influenced by an existing emitter on the rear side during the firing step, ECV measurements were performed. Figure 5 shows the results for a one- and double-sided emitter cell.

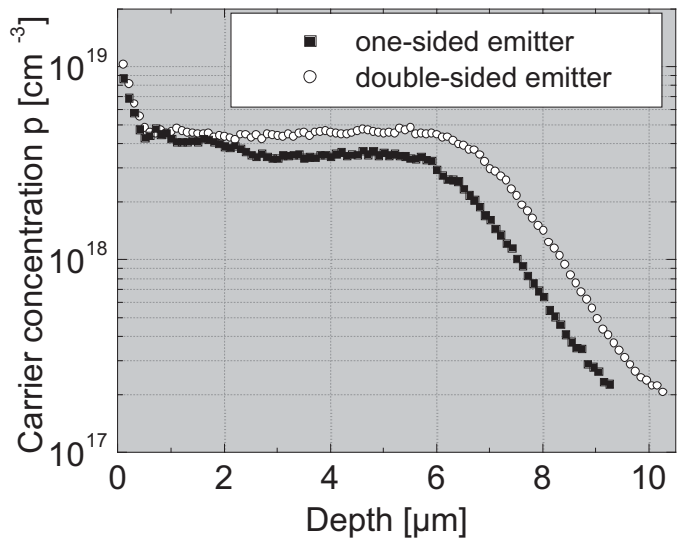

Figure 5: BSF profiles of two solar cells measured by ECV.

The differences shown in figure 5 are within measurement uncertainties of the ECV method for mcmaterial. Therefore the carrier concentration and depth of the BSF cannot explain the difference in $\mathrm{V}_{\text {oc }}$.

\section{Phosphorus compensation}

For double-sided emitter cells the in-diffused phosphorus on the rear side has to be over-compensated, made electrically inactive or released and removed during contact formation to result in an effective BSF, shown in Figure 5.

In order to determine the region where the phosphorus atoms are accumulated after contact formation, X-ray fluorescence measurements have been performed on both standard and back-to-back diffused solar cells. Firstly, the phosphorus concentration was measured on the front side to determine the X-ray count rate for a standard $50 \Omega /$ emitter. Then the count rate was measured on the rear side of both the standard and back-to-back diffused cells with and without the Al-contact (etched off with $\mathrm{HCl} / \mathrm{HNO}_{3}$ ). For comparison, the 
phosphorus background was measured on an as-grown Si-wafer with similar surface properties.

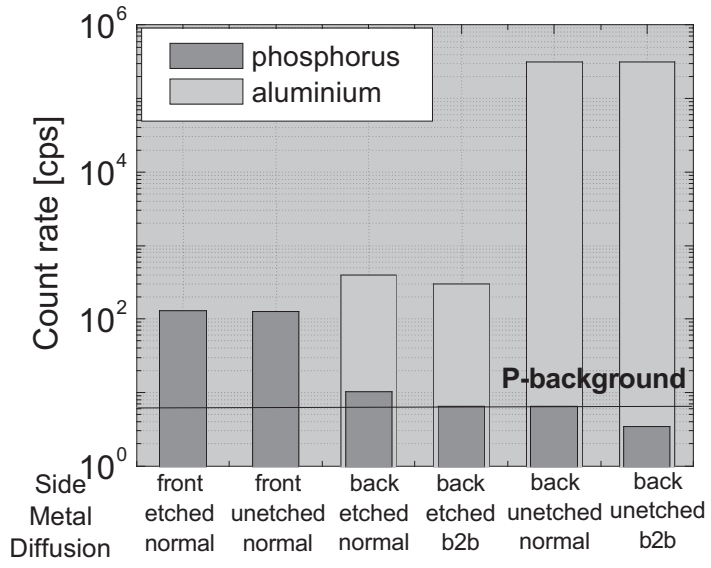

Figure 6: X-ray fluorescence measurements of P-emitter and the rear side of the one- (b2b) and double-sided (normal) emitter solar cells with and without Al back contact.

The results are summarized in Figure 6 and show in all cases a phosphorus count-rate on the rear side reduced by a factor of 10 (close to the P-background). As the matrix in the case of the etched rear side is basically $\mathrm{Si}$ (and the penetration of the X-rays in this case is greater than $100 \mu \mathrm{m}$ ) it can be concluded that the P-content in the $\mathrm{Al}-\mathrm{BSF}$ region is negligible for both solar cell processes. $\mathrm{A}$ small $\mathrm{P}$-content is suspected to remain in the BSF of the solar cell processed with double-sided emitter as the Pcount rate is slightly over the P-background. As the penetration depth of the X-rays in an Al-matrix is lower and the $\mathrm{Al} / \mathrm{Si}$ eutectic is thicker than the Al-BSF, the Patoms may have been segregated into the rear contact even if they can not be detected by this method. Therefore we believe that this method is not suited to detect phosphorus in aluminium.

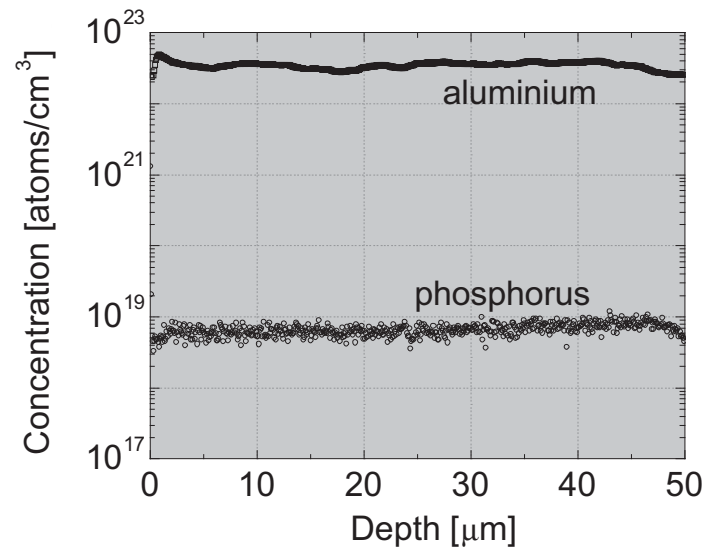

Figure 7: SIMS profile of the entire depth of the Al/Si eutectic detecting $\mathrm{Al}$ and $\mathrm{P}$ in the solar cell processed with the standard sequence.
In order to investigate this hypothesis, SIMS measurements of the Al/Si eutectic have been performed at CEA/Genec in Grenoble, France. The measurement on the rear of the standard solar cell is depicted in Figure 7. This measurement clearly demonstrates that almost the entire phosphorus atoms are distributed in the $\mathrm{Al} / \mathrm{Si}$ eutectic with a slight increase towards the Si interface. The average concentration of $7 \times 10^{18}$ atoms $/ \mathrm{cm}^{3}$ in a depth of $50 \mu \mathrm{m}$ corresponds to the concentration of the Patoms within a $50 \Omega /$ emitter with a junction depth of 0.5 $\mu \mathrm{m}$. The phosphorus concentration in the Al/Si eutectic of the back-to-back solar cell was under the detection limit.

\section{CONCLUSIONS AND OUTLOOK}

In this work we investigated the gettering effect of back-to-back diffused wafers resulting in one-sided emitter cells as compared to standard double-sided emitter cells.

Minority carrier lifetimes strongly depend on the diffusion method and we found a decreased efficiency of about $0.3 \%$ for one-sided emitter cells. This emphasizes a performance loss if industry uses back-to-back diffusion and has to be balanced by higher throughput.

With different amount of paste we could demonstrate that the gettering is not influenced by the Al layer thickness for double-sided emitter cells. Furthermore, ECV measurements showed that the BSF formation is not significantly influenced by the presence of phosphorus.

X-ray fluorescence measurements could not clarify the open question in which region the phosphorus is left after BSF formation. Additional SIMS measurements were carried out demonstrating that almost the entire phosphorus atoms are distributed in the $\mathrm{Al} / \mathrm{Si}$ eutectic with a slight increase towards the Si interface

\section{ACKNOWLEDGEMENTS}

We would like to thank N. Gawehns and A. Helfricht for technical assistance during solar cell processing. The help of $B$. Terheiden and T. Pernau during solar cell processing and P. Holliger for SIMS characterisation is also gratefully acknowledged. This work was supported by the German BMU project under contract number 0329914A.

\section{REFERENCES}

[1] A. Kränzl, R. Kopecek, K. Peter, E. Rüland, P. Fath, Proceedings of the 19th EC PVSEC, Paris, 2004, p. 1041

[2] M. Kaes, S. Seren, T. Pernau, G. Hahn, Proceedings of the 19th EC PVSEC, Paris, 2004, p. 484

[3] O. Schultz, S. Riepe, S. W. Glunz, Proceedings of the 19th EC PVSEC, Paris, 2004, p. 516

[4] P. Geiger, G. Kragler, G. Hahn, P. Fath, Solar Energy Materials \& Solar Cells, 85, 2005, p. 559 